\title{
Density dependence and the economic efficacy of marine reserves
}

\author{
Crow White
}

Received: 1 August 2008 / Accepted: 20 January 2009/Published online: 5 March 2009

(C) The Author(s) 2009. This article is published with open access at Springerlink.com

\begin{abstract}
Predictions on the efficacy of marine reserves for benefiting fisheries differ in large part due to considerations of models of either intra- or inter-cohort population density regulating fish recruitment. Here, I consider both processes acting on recruitment and show using a bioeconomic model how for many fisheries density dependent recruitment dynamics interact with harvest costs to influence fishery profit with reserves. Reserves consolidate fishing effort, favoring fisheries that can profitably harvest low-density stocks of species where adult density mediates recruitment. Conversely, proportion coastline in reserves that maximizes profit, and relative improvement in profit from reserves over conventional management, decline with increasing harvest costs and the relative importance of intra-cohort density dependence. Reserves never increase profit when harvest cost is high, regardless of density dependent recruitment dynamics. I quantitatively synthesize diverse results in the literature, show disproportionate effects on the economic performance of reserves from considering only inter- or intra-cohort density dependence, and highlight fish population and fishery dynamics predicted to be complementary to reserve management.
\end{abstract}

Keywords Density dependence $\cdot$ Fishery profit . Intercohort - Intracohort - Marine reserves · Recruitment . Stock effect

Electronic supplementary material The online version of this article (doi:10.1007/s12080-009-0039-3) contains supplementary material, which is available to authorized users.

C. White $(\bowtie)$

Marine Science Institute, University of California,

Santa Barbara, CA 93106, USA

e-mail: crowsfeather@gmail.com

\section{Introduction}

Ever-increasing fishing pressures have accelerated demand for no-take marine reserves as a biodiversity conservation tool (Wood et al. 2008). Some assert that reserves may also benefit fisheries, containing or reversing declines in fish stocks and fishery harvest rates (Gerber et al. 2003, and references therein). Under this "win-win" situation, conservation of source stocks in reserves increases catch levels in fished areas through adult spillover and larval export across reserve boundaries. Increased catch levels compensate for the displacement of fisheries from protected areas, enhancing fishery yields beyond that attainable under sustainable conventional, quota-based management (Hastings and Botsford 1999; Neubert 2003; Gaylord et al. 2005).

Maximizing fishery yields and/or profits with reserves can generate lower stock densities in unprotected areas than under conventional management (Parrish 1999). Consequently, results from bioeconomic models are sensitive to assumptions about the response of fishery economic and fish demographic processes to low stock densities. Density dependent harvest costs and density dependent fish survival have been shown to influence fishery yields and profits with reserves (White and Kendall 2007; White et al. 2008); yet, their interactive effects on fishery management have not been fully explored.

Per-unit operating cost of fishing is sensitive to the size of the exploited population (the "stock effect"; Clark 1990). Consequently, high costs of harvesting low density populations can erode profits (Hannesson 2007). The stock effect varies among fishery species and harvest methods (Sandberg 2006; Hannesson 2007). For some fisheries (e.g., those targeting abalone, rays, and groupers), the stock effect is apparently weak and has not dissuaded overexploitation (Dulvy et al. 2003). For others (e.g., those harvesting cod 
and saithe), the stock effect is nontrivial and can substantially affect profits (Hannesson 2007). In such cases, prohibitively high harvest costs associated with low stock densities can cause cessation of fishing or shifts in target species (Sala et al. 2004; Roberts 2007; but see Essington et al. 2006). Current depletion of many fisheries species stocks to $<10$ $20 \%$ their original levels (Myers and Worm 2003; Stobutzki et al. 2006; Worm et al. 2006) marks an upper limit of when this may occur in some modern fisheries (for a discussion of exceptions, see Essington et al. 2006; Polacheck 2006).

Harvest cost is a long-standing, influential factor in bioeconomic fisheries models (Gordon 1954). The stock effect in particular has significantly influenced conclusions on the efficacy of reserves. Smith and Wilen (2003) demonstrated that harvest costs in relation to stock density (along with other economic factors such as travel cost) can decrease the value of reserves. Using a static bioeconomic model with the stock effect, Armstrong and Skonhoft (2006) showed that management focused on maximizing yield with reserves can reduce profit. In one of the few papers to explicitly consider the stock effect under a broad range of fish population and fishery harvest conditions, Sanchirico et al. (2006) analyzed a two-patch model and found closure of one patch to increase profit only under heterogeneous conditions. Using a model with similar assumptions to Sanchirico et al., White et al. (2008) introduced space as a continuous, linear coastline and assumed that dispersal is localized; they found that reserves can increase profit when patches were homogeneous as long as reserve configuration and harvest were optimized for the economic and biological features of the fishery.

Density-dependent demographic processes in marine species are variable and challenging to assess (Minto et al. 2008). In principle, a finite availability of local resources limits recruitment (defined here as survival of settlers to the adult stage) in relation to local adult (inter-cohort) and settler (intra-cohort) population densities. Empirically, recruitment is affected by conspecific and heterospecific competition for food and refuges with other settlers and with incumbent adults and predation by heterospecific adults (e.g., Webster 2004; Hixon and Jones 2005; Johnson 2006b; Schmitt and Holbrook 2007). Most studies of density-dependent recruitment in marine systems are of non-fishery species that are, not coincidentally, small and not piscivorous (e.g., see meta-analysis by Osenberg et al. 2002). For several fishery species (e.g., bass, rockfish, crabs, clupeids, and gadids), conspecific adult density may influence recruitment beyond that from competition alone due to predation by cannibalistic adults (Smith and Reay 1991; Folkvord 1997; Hobson et al. 2001; Wahle 2003; Durant et al. 2008b).

Bioeconomic studies evaluating reserves have considered inter- and intra-cohort density-dependent recruitment processes separately. Among those focused on fishery yield, conclusions range from increased (given intercohort density dependence) to at best equivalent (intracohort density dependence) yields from reserves compared with those attainable under conventional management (e.g., Hastings and Botsford 1999; Gaylord et al. 2005). The difference in results is linked to the functional forms of density dependence, only one of which (inter-cohort) promotes increased recruitment with reduced local adult density due to increased harvest pressure (White and Kendall 2007). Recasting yield-based studies with consideration of the stock effect complicates and potentially widens the difference in results because intensive fishing between reserves can reduce profits (Sanchirico 2005; Sanchirico et al. 2006; White et al. 2008). To date, there has been no consideration of the effect of reserves on profits to fisheries targeting species exhibiting both interand intra-cohort density-dependent recruitment.

Here, I provide an analytic framework that quantitatively synthesizes disparate conclusions of the literature on the economic efficacy of reserve-based management. Using a bioeconomic model of nearshore fish population and fishery dynamics, I consider the stock effect and coupled inter- and intra-cohort density-dependent recruitment processes. I demonstrate how, with the exception of fisheries experiencing high stock effect conditions, harvest costs and recruitment dynamics interact nonlinearly to influence relative maximum profits between reserve and conventional management. I identify past conclusions that result from considering endpoints of a continuum of density dependent and stock effect conditions and relate these results to each other and to results here generated under interior biological and economic conditions. I highlight the limited range of stock effect and density dependent conditions - and discuss associated fisheries and species - suggested by the results to be more favorable to reserve management. Finally, I outline biological and socioeconomic factors important to the evaluation of fishery management that have yet to be considered collectively.

\section{Methods}

I developed a spatially and temporally explicit integrodifference model for representing fish and invertebrate species characterized by a sessile adult stage subject to densityindependent mortality and a pelagic larval stage that disperses:

$$
\begin{aligned}
A_{x}^{t+1}= & A_{x}^{t}-H_{x}^{t}-M\left(A_{x}^{t}-H_{x}^{t}\right) \\
& +\int_{-\infty}^{\infty}\left(A_{x^{\prime}}^{t}-H_{x^{\prime}}^{t}\right) P K_{x-x^{\prime}}^{t} R_{x}^{t} d x^{\prime}
\end{aligned}
$$


where $t, x$, and $x^{\prime}$ refer to time and two locations along a uniform coastline, respectively; $A=$ number of adult fish (units arbitrary); $H=$ harvest; $M=$ natural annual adult mortality probability; $P=$ adult per capita production of larvae that survive to settlement; $K_{x-x^{\prime}}=$ the proportion of larvae settling at location $x$ that originated from location $x^{\prime}$; and $R=$ recruitment probability of settling larvae. The larval dispersal kernel represented by $K_{x-x^{\prime}}$ is Gaussian, based on simulations of ocean mixing processes, and adjustable via a chosen mean larval dispersal distance $D_{d}$ (Siegel et al. 2003, and calculations therein). I evaluated the model at 1-year time steps (thus, fish enter the fishery when $c .1$ year old) and, in practice, discretized the infinite domain indicated by the integral into 1-km length segments along a circular coast. Thus, "sessile" adults include those that remain within a 1-km diameter home range, and there were no domain edge effects. I kept habitat conditions uniform throughout to exclude confounding effects of habitat quality on recruitment (Shima and Osenberg 2003; Johnson 2007).

In the model, a single prerecruit stage class precedes the adult stage class. This approach captured density-dependent recruitment processes occurring shortly after settlement (e.g., via predation), during the juvenile or subadult stage (e.g., via competition and/or territoriality) or both. Over the recruitment period, inter- and intra-cohort densitydependent processes may affect mortality simultaneously or sequentially in either order. In order to combine the two forms of density dependence in a non-arbitrary way, I developed a continuous-time model describing the period from settlement to recruitment, in which the instantaneous effects of both types act in a simple mass-action way. In the Appendix, I show that when intra- and inter-cohort density dependence both act throughout the settlement-recruitment period, the proportion of settlers that recruit locally is

$R_{x}^{t}=\frac{(D-1) N_{x}^{t} e^{\alpha D N_{x}^{t}}}{D S_{x}^{t} e^{\alpha D N_{x}^{t}}+e^{\alpha N_{x}^{t}}\left((D-1) N_{x}^{t}-D S_{x}^{t}\right)}$,

where $S_{x}^{t}$ is local settler density, $N_{x}^{t}=A_{x}^{t}-H_{x}^{t}$, the local escapement, $\alpha$ represents the overall strength of density dependence (it is a scaling parameter, controlling the equilibrium abundance), and $D$, which ranges from zero to one, describes the relative strength of inter- versus intracohort density-dependent processes. Given only intercohort density dependence, $D=0$ and the recruitment proportion simplifies to the Ricker formula (1954), reflecting an overcompensatory effect of adult density on recruitment (Webster 2004; Johnson 2006b). Given only intra-cohort density dependence, $D=1$ and Eq. 2 fails; in the Appendix, I show that when the continuous-time competition equation is recast with just intra-cohort density dependence, its solution produces the Beverton and Holt formula (1957) reflecting observed compensatory density- dependent mortality among settlers (Hixon and Jones 2005). Accordingly, I used Ricker and Beverton-Holt formulas when representing sequential density dependence during the recruitment period (Appendix, Eqs. 9 and 10). I separately incorporated each of the three life history scenarios (Eq. 2, Appendix, Eqs. 9 and 10) into Eq. 1 and standardized their effects by solving the density dependent coefficient $\alpha$ for a set equilibrium virgin carrying capacity, $A^{*}=100 \mathrm{fish} / \mathrm{km}$ in the absence of fishing (i.e., $H=0$ ).

Profit to a fishery is a function of revenue gained from selling fish yield, minus the cost of catching those fish. I modeled marginal cost of fishing to be inversely proportional to local fish density, $\theta /\left(\right.$ fish $\left.^{*} \mathrm{~km}^{-1}\right)$ (Clark 1990), where higher values of $\theta$ represent species that are intrinsically more expensive to harvest. For each $1-\mathrm{km}$ distance bin along the coast, I calculated the annual cost of harvesting by integrating along the stock effect curve from the pre- to post-harvest population density. I then subtracted local cost from local revenue, based on a fixed market price of $\$ 1 /$ fish caught locally, to estimate annual profit to the fishery generated at that location:

$\pi_{x}^{t}=H_{x}^{t * \text { price }}-\int_{z=A_{x}^{t}}^{z=A_{x}^{t}-H_{x}^{t}} \frac{\theta}{z} d z$

Let $\underline{A}$ be the fish density below which marginal cost exceeds marginal revenue; since $A^{*}=100$ fish $/ \mathrm{km}$ and price $=1, \underline{A}=\theta$. This "zero marginal profit" point represents a (marginal revenue)/(marginal cost) rate equal to one, and is the local density below which it is unprofitable in the current year to continue harvesting. As a result, $\theta$ is a standardized parameter that indicates the percentage of virgin stock below which fishing would naturally cease.

Fisheries able to extirpate local populations through overexploitation (Dulvy et al. 2003) are represented in the model by a $\theta$ near zero, indicating negligible density dependent harvest costs. Many fisheries whose profits are substantially influenced by the stock effect (Hannesson 2007) are still able to profitably exploit populations to $<10-20 \%$ the original stock (Lipcius and Stockhausen 2002; Cardinale and Svedang 2004; Worm et al. 2006), corresponding with $\theta<10-20$. To represent density dependent harvest costs experienced among these fisheries, I focused the bulk of my analysis on the range of stock effect conditions $0 \leq \theta \leq 20$. Stock effect values used here also correspond approximately with those used previously (e.g., in a two-patch model by Sanchirico et al. 2006, $\theta=25$ in one patch, and $\theta>0$ in the other patch). Fisheries not exploiting stocks to such low levels (Essington et al. 2006; Polacheck 2006) are more appropriately represented by stronger stock effect conditions (i.e., $\theta \gg 20$ ). Such high harvest costs are expected to severely limit the long-term profitability of intensive harvesting, promoting the de facto 
protection of source stocks within fished areas that can sustainably replenish the fishery without the need for larval export from protected stocks in reserves. Consequently, in my deterministic model reserve management is expected to be less beneficial for these fisheries that harvest less intensively, regardless of the density dependent recruitment dynamics of the target species. To test this prediction, I evaluated the interaction between density dependent recruitment and harvest costs across a large range of stock effect conditions that includes those representing species with exorbitant harvest costs $(0 \leq \theta \leq 95)$, using baseline model settings.

In each model scenario, I considered 19 percentages of the coast in reserves (Table 1), including $0 \%$ reserves (i.e., conventional management). I defined a reserve as an area permanently closed to fishing. For each reserve percentage, I considered a range of systematically varied reserve size and spacing configurations, represented by many small, closely positioned reserves to fewer, larger reserves positioned farther apart (Table 1). Given reserve percentage and configuration, I adjusted the circular domain's perimeter length (up to $1,500 \mathrm{~km}$ ) to maintain evenness in reserve size and spacing. The spatial breadth of this approach enabled me to capture effects from single large versus several small (SLOSS) reserve configurations. However, resolving the SLOSS debate was not the goal of this study; rather, I optimized configuration in order to maximize profit with reserves for comparison with maximum profit under conventional management. The homogeneous conditions of the model system were ideal for this exercise because it enabled me to explore all symmetrical reserve configurations possible within an exceptionally large coastal domain.
White et al. (2008) previously demonstrated a pattern of reserve configuration with respect to mean larval dispersal distance that, when evaluated across any dispersal distance, produces quantitatively identical maximum profits. However, their analysis did not consider $D>0$. To test for consistency in results with positive values for $D$, I considered mean dispersal distances 50,100, and $200 \mathrm{~km}$ under baseline model settings. I then chose to conserve computer processing time by running the full factorial of simulations for only $D_{d}=100 \mathrm{~km}$.

Given reserve percentage and configuration, I imposed each of the 98 escapement policies in Table 1 across the entire fishable domain (i.e., area between reserves). This broad range of harvest levels saddles the zero marginal profit point for each value of $\theta$, generating all reasonable (marginal revenue)/(marginal cost) rates, whether they maximized profit or not.

I compared profits under optimal reserve management with those under optimal conventional management. Optimal reserve management was the strategy characterized by reserve percentage and configuration, and escapement that maximized sustainable profit. Optimal conventional management was limited to strategies without reserves. Sustainable profit was defined as mean annual profit to the fishery across the entire domain $(\$ / \mathrm{km})$, based on equilibrium conditions (i.e., $\overline{\pi_{x}^{*}}$ ). I did not compare total fishery profit across the domain (e.g., as done by Sanchirico et al. 2006) because coast length varied among the simulations. However, due to the homogeneity of the coast, use of a circular domain (i.e., no edge effects) and symmetry of the reserve and harvest policies across the domain for all simulations, mean sustainable profit served as a direct, standardized proxy for total fishery profit whose propor-

Table 1 Symbol, value(s), and description of design parameters and variables

\begin{tabular}{lll}
\hline Parameter/variable & Values evaluated & Description \\
\hline$A^{*}$ & 100 & Equilibrium virgin population density (fish/km), in the absence of fishing. \\
$M$ & $0.05,0.1,0.2,0.3$ & Natural adult mortality probability \\
$P$ & $1,2,3$ & Adult per capita production of larvae that survive to settlement \\
$R_{x}^{t}$ & 3 equations (see text) & Recruitment probability function \\
$\alpha$ & Solved for $R=\mathrm{M} / \mathrm{P}$, given $H=0$ & Density dependent recruitment coefficient, where $R=$ proportion settlers that recruit \\
$D_{d}$ & $50,100,200$ & Mean larval dispersal distance $(\mathrm{km})$ \\
$P r i c e$ & 1 & Price $(\$$ per fish) $=$ marginal revenue \\
$\theta$ & $0,1,2, \ldots, 95$ & Stock effect coefficient $(\$ / \mathrm{km})$ \\
$D$ & $0,0.05,0.1, \ldots, 1$ & Inter- versus intra-cohort density dependent recruitment scaling parameter \\
$\left(A_{x}-H_{x}\right) /\left(A^{*}\right)$ & $0.01,0.02,0.03, \ldots, 0.99$ & Escapement \\
Frac $\left(x\left[H_{x}=0\right]\right)^{*} 100$ & $0,5,10,15, \ldots, 95$ & Percentage of the coast in reserves \\
Domain & $10-1,500$ & Coast length $(\mathrm{km})$ \\
Reserve width & $1-1,425$ & Length of a reserve along the coast $(\mathrm{km})$ \\
Reserve spacing & $2-1,500$ & Distance between reserve centers $(\mathrm{km})$ \\
\hline
\end{tabular}

Fish units are numerical and arbitrary. Marginal cost equals marginal revenue when $\left(\mathrm{A}^{*}\right)($ escapement $)=\theta \%$ 


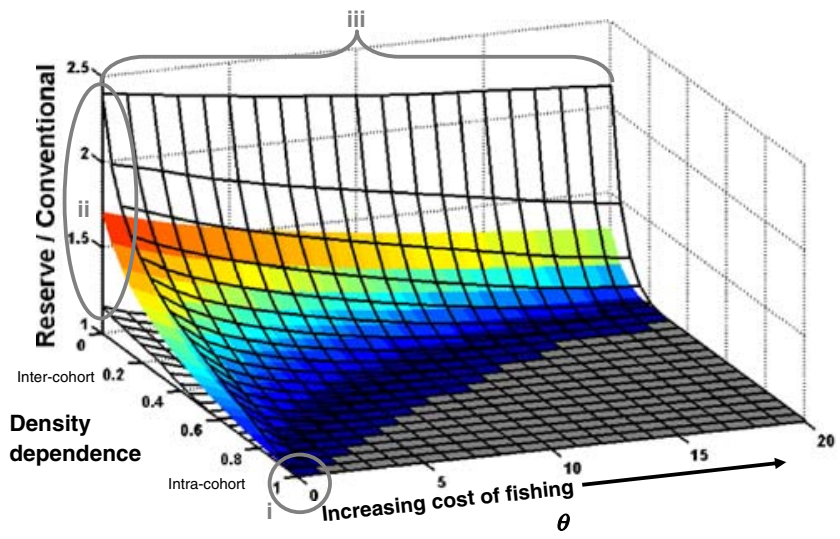

Fig. 1 Mean (surface) \pm maximum/minimum (grids) relative fishery profit under optimal reserve versus optimal conventional management, as influenced by the stock effect $(\theta)$ and inter-relative to intra-cohort density dependent recruitment processes ("Density dependence", $D$ ). Values greater than one indicate reserves were optimal and increased fishery profit; values equal to one indicate conventional management was optimal. Grey region indicates parameter space over which reserves were never optimal. Means and ranges summarize results across all adult productivity and adult natural mortality parameter values, and three recruitment life history scenarios listed in Table 1. Marked regions highlight duplication of results from previous studies: i (Hastings \& Botsford 1999), ii (Gaylord et al. 2005; White \& Kendall 2007), and iii (White et al. 2008)

tional differences could be compared among management conditions. Profit-maximizing solutions were determined through exhaustive simulation across the full factorial of control variables, rather than via an optimal control formulation (e.g., by Sanchirico et al. 2006 and references therein).

\section{Results}

For fisheries characterized by low to moderate stock effect conditions $(0 \leq \theta \leq 20)$, simulation results revealed an inter- action between density dependent harvest cost (scaled by $\theta$ ) and recruitment (scaled by $D$ ) dynamics that promotes increased profits with reserves across approximately half the parameter space (Fig. 1; note that because the parameter set for reserve management includes $0 \%$ reserves, the ratio in this figure can never be less than one). Within this space the efficacy of reserves for increasing profit decayed exponentially as the stock effect increased $(\theta \rightarrow 20)$ and the relative importance of intra-cohort density dependence increased $(D \rightarrow 1)$. Simultaneously, the percentage of the coast in reserves that maximized profit decreased from more than $50 \%$ to $0 \%$ (Fig. 2a). Across the remaining half of the parameter space, conventional management maximized fishery profit.

To compensate for displaced fishing pressure from protected areas, optimal reserve management always included more intensive local fishing pressures (i.e., lower escapement) that lead to lower stock densities in nonreserve areas than existed under optimal conventional management (Fig. 2b). Escapement decreased with increasing percentage of the coast in reserves, reaching a minimum at $(D=0$ and $\theta=0)$. Conversely, when conventional management maximized profit escapement increased monotonically with stock effect severity but without regard to $D$ because harvest and population dynamics were spatially homogeneous throughout the domain. For fisheries experiencing stronger stock effect conditions $(\theta>20)$, high harvest costs increased the lower bound of escapement that maximized profit. As a result, reserve management - and its reliance on low escapement-was never optimal, regardless of density dependent recruitment dynamics (Electronic supplementary material, Fig. S1).

The range of results generated across the full factorial of adult natural annual mortality probability $(M)$ and per capita larval productivity $(P)$ values in Table 1 are illustrated by \pm
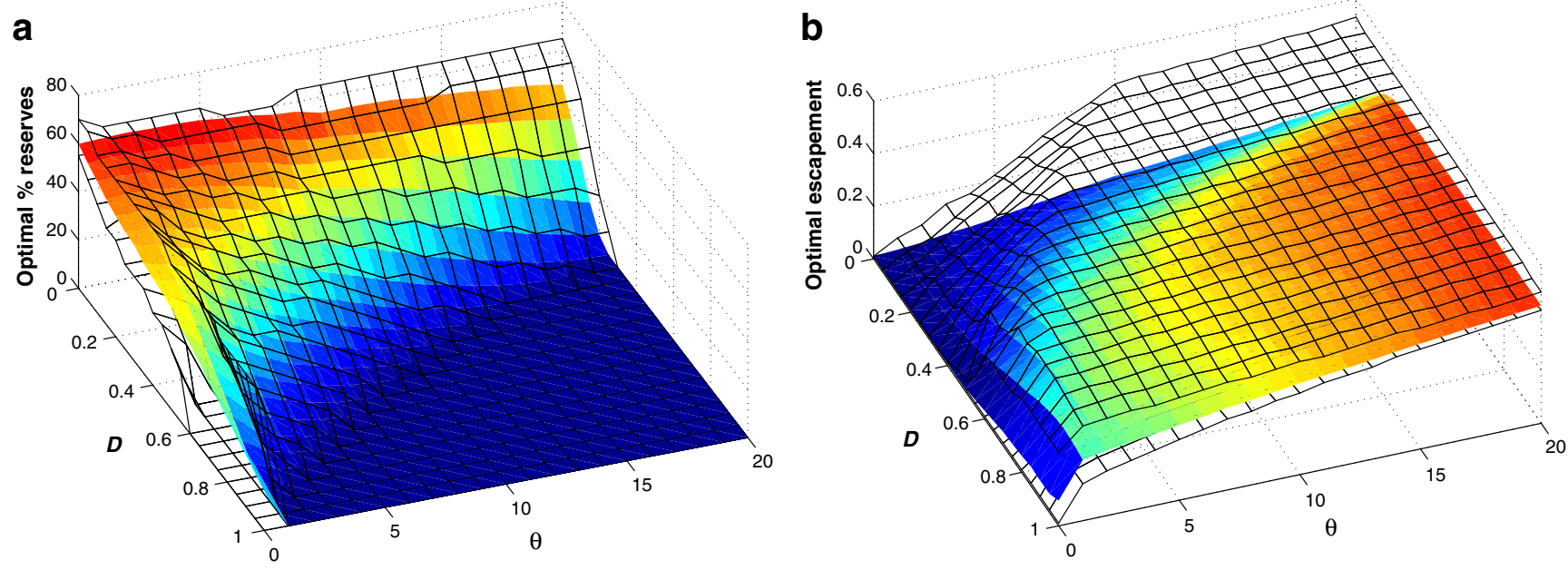

Fig. 2 Mean (surfaces) \pm maximum/minimum (grids) percentage of the coast in reserves a and escapement in unprotected areas $\mathbf{b}$ that maximized fishery profit. Statistics based on values and scenarios stated in Fig. 1 
maximum/minimum grids in Figs. 1 and 2. Demographic values influenced the proportional difference in profit generated under reserve versus conventional management (as illustrated by the vertical span of the grids in Fig. 1), with lower mortality and/or larger productivity having an amplifying effect. However, variance in the demographic values only minimally influenced which management strategy was optimal across the $\theta$ by $D$ parameter space; lower mortality and/or higher productivity values slightly increased the parameter space over which reserves maximized profit.

Differences in the relative timing of intra- and inter-cohort density dependent recruitment processes - represented by three different recruitment functions - had a negligible influence on the proportional difference in profit between reserve and conventional management or which management strategy maximized profit across the $\theta$ by $D$ parameter space (Fig. 3a).
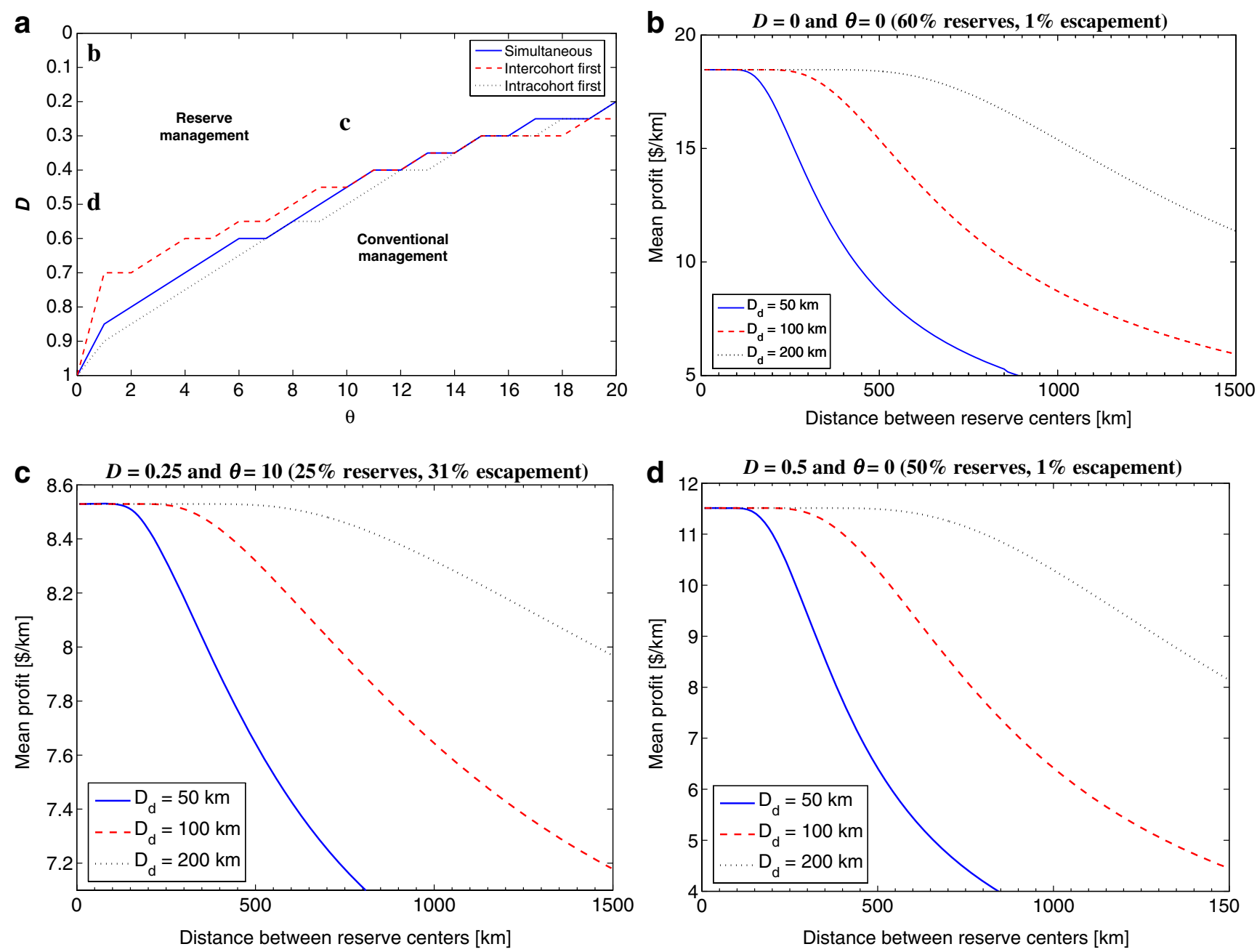

Fig. 3 Contours dividing the $D$ by $\theta$ parameter space into regions where fishery profit was maximized by either reserve or conventional management a. Each line corresponds with a different density dependent recruitment life history scenario (see legend). A line marks where - on average across results produced under the full factorial of $P$ by $M$ values in Table 1 - the percentage of the coast in reserves that maximized profit changed from positive values to zero. Note similarity in results among the three life history scenarios. Letters $b$, $c$, and $d$ within panel a mark density-dependent and stock-effect parameter settings corresponding with panels (b-d), which illustrate the effect of reserve configuration on profit for different mean larval dispersal distance values $\left(D_{d}\right.$; see legend). For each panel, percentage

of the coast in reserves and escapement are set at values that maximized profit, given simultaneous inter- and intra-cohort density dependence, $P=1$ and $M=0.1$, and density-dependent and stock-effect conditions (see panel titles). Width of a single reserve equals the proportion of the coast dedicated to reserves multiplied by the distance between reserve centers (e.g., in panel (d), given $D_{d}=50 \mathrm{~km}$, profit was maximized when the distance between reserve centers was approximately less than $100 \mathrm{~km}$, which, given $50 \%$ reserves, corresponds with an individual reserve width $<50 \mathrm{~km}$ ). Consistent across all model runs, when reserves maximized profits, maximum or near maximum profits were generated when reserve width was equal to or less than mean dispersal distance 
When reserves increased profit, there was a consistent pattern characterizing optimal reserve configuration in relation to mean larval dispersal distance: given a specified percentage of the coast in reserves (e.g., that maximized profit), maximum or near maximum profits were generated when reserve width was equal to or less than the mean larval dispersal distance of the fishery species (Fig. 3b-d).

\section{Discussion}

Previous analytical and numerical models focused on margins of the $\theta$ by $D$ parameter space can be seen as special cases of the current model. Studies presenting substantial benefits from reserves given $\theta=0$ and $D=0$ (e.g., Gaylord et al. 2005; White and Kendall 2007) represent a corner solution where intensive fishing maximizes recruitment of settlers exported from source stocks protected in reserves, generating sustainable high yields and revenues that are unmitigated by harvest costs. Relaxing only the stock effect assumption $(\theta>0$; e.g., White et al. 2008) reduces but not necessarily negates increased profits with reserves. Given only intra-cohort density dependence ( $D=1$; e.g., Hastings and Botsford 1999), which is not expected to favor reserves because local recruitment cannot be directly mediated by local harvest pressure, equivalent profits are generated with reserves under a zero-escapement ("scorched earth") fishing strategy that is cost-free and that generates revenues equal with those under conventional management. Relaxing the stock effect assumption while maintaining $D=1$ introduces high harvest costs at low escapement, eroding profits with reserves below those attainable under optimal conventional management.

Results support previous conclusions that increased returns from reserves can occur when larval export or spillover from the reserves is not muted during recruitment (Sanchirico et al. 2006) and that returns with reserves are strongest when recruitment is dependent on the harvested stock density (Sanchirico 2005; Ralston and O'Farrell 2008). The above studies by Sanchirico, Ralston, and O'Farrell are based on patch models and are not replicated exactly here; however, all contain assumptions and conclusions that are qualitatively congruent with those presented here for $D=0$ and 1 .

Inter- and intra-cohort forms of density dependence induced disproportionately different effects on the relative economic performance of reserves. Specifically, the concave shape and orientation of the surface in Fig. 1 illustrates that focus on inter-cohort density dependence (e.g., by assuming it to affect recruitment exclusively) can generate greatly increased profits with reserves, while focus on intracohort density dependence only marginally reduced profits with reserves, compared with that under interior conditions
$(0<D<1)$. The disproportionate effects dissipated only when harvest costs were high (i.e., $\theta>20$, Electronic supplementary material, Fig. S1). Although the recruitment functions used here can be deconstructed into components familiar in fisheries models (Ricker 1954; Beverton and Holt 1957), to my knowledge, this is the first study to explicitly couple them when evaluating fishery management. The dearth of empirical estimations on the relative strengths of inter- and intra-cohort density dependent processes, along with the desire to avoid overly-embellished models that introduce unnecessary uncertainty and veil salient dynamics (May 2004; Pelletier et al. 2008), has understandably motivated theoretical ecologists to avoid the recruitment functions evaluated here. Yet, given the growing number of spatial, dynamic fisheries models that allow settlement to be spatially and/or temporally uncoupled from local adult density (Pelletier et al. 2008), this study emphasizes the importance in considering explicitly coupled density dependence when evaluating reserve management for fisheries with low to moderate harvest costs. In contrast, the relative timing of inter- and intra-cohort density dependence (represented by the three different density dependent life history scenarios) minimally impacted results, suggesting that it is less important for fisheries models to explicitly consider this factor.

Regardless of density dependent dynamics, reserves that were small relative to mean larval dispersal distance were preferred because they maximized larval export, while ensuring population persistence within reserves through inter-reserve dispersal - $\mathrm{a}$ result supported by previous studies (Neubert 2003; Gaylord et al. 2005; White et al. 2008). Consistency in optimal reserve size and spacing with respect to dispersal distance was due to the coast being continuous and homogeneous, enabling reserve configuration to be always scalable in relation to dispersal distance. The symmetry of the optimal configurations, due to the simplified characterization of the coast and symmetrical dispersal kernel, should not be interpreted as literal guidance for fisheries management. In practice, evenness in reserve spacing is likely not optimal in a spatially heterogeneous system (Sanchirico 2004; Kaplan 2006).

Adult density-independent demographic parameter values influenced the magnitude of the proportional difference in profit between reserve and conventional management but not the $\theta$ by $D$ parameter space over which reserves maximized profit. Increased fish population growth rate, which corresponds with increased larval productivity and/or reduced adult natural mortality, widened the difference in maximum profit under reserve versus conventional management by inducing equal proportional increases in profits to each strategy without changing which one was optimal. Consequently, for a specified $\theta$ and $D$, both management strategies were more profitable, but the optimal one 
preferentially so, for high-growth species. Similar trends have been found previously (Gaylord et al. 2005; White and Kendall 2007; White et al. 2008).

Fisheries that could profitably harvest low-density populations (i.e., those characterized by low $\theta$ ) were more likely to benefit from reserves. Aggregative species (e.g., abalone and grouper, whose adults cluster even when the over stock is sparse) can under some conditions be relatively profitable to harvest at low density (Officer et al. 2001; Sadovy and Domeier 2005). Fisheries harvesting multiple, sympatric species also have the potential to profitably harvest low-density populations of the secondary species when effort is driven by a more abundant or remunerative primary species (Bene and Tewfik 2001; Dulvy et al. 2003). Improvements in fish locating and harvesting technologies and use of management policies (e.g., those with dedicated access privileges) that mitigate against competition among fishermen also have the potential to make fisheries more cost-effective at harvesting lowdensity stocks (Gordon 1954; Hannesson 1991; Grafton 1996; Joyce 1997; Grafton et al. 2000; Hilborn et al. 2003; O'Neill et al. 2003; Fujita and Bonzon 2005; Hilborn et al. 2005; Newell et al. 2005; Costello and Deacon 2007). Although not necessarily optimal, reserve management may be more beneficial to certain fisheries under such conditions. In contrast, results here indicate reserves to not benefit fisheries that are unable to profitably harvest stocks below $20 \%$ unfished levels.

Target species more favorable to reserve management were those with recruitment mediated by adult density $(D \rightarrow 0)$. Quantifying the relative influence of inter- versus intra-cohort density dependence in fishery species remains a major challenge (Hixon and Jones 2005). Because fisheries (e.g., in California, CDFG 2008) are often biased toward large predatory species, the abundance of evidence for intra-cohort density dependence in non-fishery species (e.g., Osenberg et al. 2002; Hixon and Jones 2005; Schmitt and Holbrook 2007) does not by itself confirm that it dominates in fishery species. Many fishery species (e.g., bass, rockfish, crabs, cod) are at the least implicated to exhibit inter-cohort density dependence through observations of cannibalism (e.g. Smith and Reay 1991; Folkvord 1997; Hobson et al. 2001; Wahle 2003; Durant et al. 2008b). However, evidence for intra-cohort density dependence in some of these species (e.g., rockfish, bass; Johnson 2006a; White and Caselle 2008) highlights its persistent influence on recruitment in the presence of intercohort predatory processes. Collectively, these observations suggest that for most fishery species, intra-cohort density dependence likely overshadows inter-cohort density dependence, but for some species - particular predatory ones- inter-cohort density dependence may be relatively strong. All else being equal, reserves may increase profit to fisheries targeting these species.

Although $\theta$ and $D$ interactively influence profit with reserves, I find no evidence in the literature for a correlation between the stock effect describing a fishery and densitydependent recruitment dynamics of its target species. For instance, fishery species that aggregate and shoal (making them more cost-effective to harvest) exhibit variable levels of inter-cohort density dependence (e.g., Day et al. 2004; Slotte et al. 2006; Durant et al. 2008a). Consequently, independent estimation of both factors is likely necessary for a comprehensive evaluation of fishery management.

Social, political, and economic challenges in adopting, designing, and enforcing reserves can, in practice, lead to fixed reserve locations, representing a single percentage of the coast across multiple fisheries (Davis 2005). Yet, fisheries characterized by different $D$ and $\theta$ values are associated with different profit-maximizing percentages of the coast in reserves (from $0 \%$ to over $50 \%$, Fig. 2a), suggesting potentially deleterious effects from closing a single percentage of a region to multiple fisheries. Indeed, setting reserve percentage constant caused maximum profits with reserves relative to those under optimal conventional management to increase and decrease equally — by as much as $240 \%$ - for fisheries characterized by $(D$ and $\theta \rightarrow 0)$ or $(D \rightarrow 1$ and $\theta \rightarrow 20$ ), respectively (Electronic supplementary material, Fig. S2). Given that it may be impractical to tune management to each fishery, an alternative approach is to calculate the percentage in reserves that maximizes cumulative fishery profit. As is done here, an exhaustive sampling scheme of the full structure of the objective function could be especially informative for assessing economic consequences of various reserve designs among multiple fisheries (e.g., by Meester et al. 2004). I predict results from such an analysis to strongly depend on the $D$ by $\theta$ frequency distribution of the fisheries and their target species in the management region.

In this study, I demonstrate how biological and economic factors interact to influence fishery profit. I emphasize the importance of coupled inter- and intra-cohort density dependent recruitment - a process not considered explicitly in previous fishery models. There are many other factors regulating fish population and fishery dynamics that I do not consider. For example, pre-dispersal density dependence (e.g., in adult fecundity; McClanahan and Kurtis 1991; Nash et al. 2000; Tomas et al. 2005) that may reduce benefits from reserves due to lower per capita production levels of larvae by high stock densities in reserves; effects of high harvest pressures between reserves that may reduce recruitment through habitat degradation (e.g., via trawling; 
Hiddink et al. 2006; Queiros et al. 2006); larval and/or juvenile growth that may introduce complex and/or destabilizing stage-structured dynamics, especially when harvesting is intensive (Anderson et al. 2008; Hamilton et al. 2008); and economic factors such as added travel and enforcement costs with reserves (Smith and Wilen 2003), public subsidies that lower marginal costs experienced by fisheries (particularly those receiving marginal subsidies, e.g., fuel) but extol societal costs not explicitly included in $\theta$ (Kaczynski and Fluharty 2002), and the discounted value of future profits. Consideration of the effect of a positive discount rate on equilibrium profit using my numerically optimized dynamic model is challenging; however, based on that shown by Sanchirico et al. (2006) using an analytical model, I expect a low/zero discount rate (as assumed here) to favor reserves because it promotes preservation of a high stock density (in reserves) for generating future valuable profits. Timing of harvest may also be important to results. For example, larval production and settler survival in relation to pre- (instead of post-) harvest stock density will weaken the link between escapement and inter-cohort density dependence, thereby reducing recruitment to heavily fished areas between reserves.

Other assumptions in my model bias results against reserve management. For example, I ignore environmental and demographic stochasticity; heterogeneity in (1) habitat quality, (2) larval dispersal patterns, and (3) harvest pressure across the fishing area; and uncertainty in knowledge of the state of the system or regulation by managers of policies, all of which can increase relative profits from reserves (Lauck et al. 1998; Sumaila 1998; Armsworth and Roughgarden 2003; Stefansson and Rosenberg 2005; Sanchirico et al. 2006; Ralston and O'Farrell 2008). I also disregard adult movement and growth, which may, under some conditions, favor reserve management; the former through adult spillover (Alcala et al. 2005; but see Sanchirico 2005), the latter, through increased production of larvae by older/larger adult fish, protected within reserves (Marteinsdottir and Begg 2002; Gaylord et al. 2005; but see Gårdmark et al. 2006 and Hart and Sissenwine 2009). In addition to improved empirical parameterization of $\theta$ and especially $D$ and their explicit integration into reserve models, important to management decisions is the determination of how relaxing the above assumptions changes the parameter space over which I have found reserves to increase profit.

Acknowledgements I am grateful to Bruce Kendall, Robert Warner, and David Siegel of the Flow, Fish, and Fishing research team; Steven Gaines and Christopher Costello of the Sustainable Fisheries Group; Hunter Lenihan and Jono Wilson of the Collaborative Fisheries
Research Group and Alan Hastings and two anonymous reviewers for providing helpful comments that dramatically improved the quality of this manuscript. Support was provided by the National Science Foundation (grant number OCE-0308440) and The Canon National Parks Science Scholars Program.

Open Access This article is distributed under the terms of the Creative Commons Attribution Noncommercial License which permits any noncommercial use, distribution, and reproduction in any medium, provided the original author(s) and source are credited.

\section{Appendix}

Mathematical derivation of density dependent life history scenarios. I modeled inter- and intra-cohort density dependent mortality proceeding simultaneously by integrating juvenile abundance from settlement (time 0 ) to recruitment (time $T$ ):

$\frac{d J_{x}}{d t}=-\alpha\left((1-D) J_{x} N_{x}+D J_{x}^{2}\right)$

where $J_{x}$ is local juvenile density; $N_{x}=A_{x}-H_{x}$, the local escapement or density of adults left unharvested; $D$, which ranges from 0 to 1 , the relative per capita effect on juvenile survival by adults and juveniles, respectively; and $\alpha$ a positive number characterizing the overall severity of density dependent regulation. This model is modified from Verhulst's (1838) original formulation of the continuoustime logistic model, characterizing negative 'growth' in response to a mass interaction between juveniles and adults, and a mass interaction between juveniles and themselves. The recruitment rate is defined as the ratio of the final to initial juvenile density:

$R_{x}=\frac{J_{x}^{T}}{J_{x}^{0}}$,

where $J_{x}^{0}=S_{x}$, the initial density of juveniles, or settler density. Over the recruitment period local adult density is assumed to be constant (or at least uncoupled with local settler density). This assumption is violated when, for example, predatory adults are highly mobile and aggregate from throughout a region to a local settlement. Equation 4 can be solved to describe the proportion of settlers that recruit over the discrete time period $T=1$. Given only intercohort density dependence, $D=0$ and

$R_{x}=e^{-\alpha N_{x}}$,

as shown by Ricker (1954). Given only intra-cohort density dependence, $D=1$ and

$R_{x}=\frac{1}{1+\alpha S_{x}}$, 
as shown by (Beverton and Holt 1957). With both forms of density dependence $(0<D<1)$, the solution to Eq. 4 is

$R_{x}=\frac{(D-1) N_{x} e^{\alpha D N_{x}}}{D S_{x} e^{\alpha D N_{x}}+e^{\alpha N_{x}}\left((D-1) N_{x}-D S_{x}\right)}$,

which, to my knowledge, has not been presented before.

I used Eqs. 6 and 7 when representing sequential density dependence life history scenarios. Inter-cohort followed by intra-cohort density dependence was considered to represent predatory effects on mortality that may be most apparent early in the recruitment period when settlers are small and easily preyed upon by adults (Hobson et al. 2001; Steele and Forrester 2002; Johnson 2006a). Given intercohort followed by intra-cohort density dependence,

$R_{x}=\frac{e^{-\alpha(1-D) N_{x}}}{1+\alpha D\left(S_{x} e^{-\alpha(1-D) N_{x}}\right)}$,

where the term in parentheses represents the number of settlers remaining after inter-cohort density dependence has acted. I considered intra-cohort density dependence proceeding that involving adult density to represent species (e. g., rockfish, lobster, opaleye) where settlers initially utilize and compete for resources in a microhabitat (shallow water zone, kelp forest canopy) different than that used by the adult cohort and only later as sub-adults spatially intermix with and compete for resources with adults (e.g., Norris 1963; Love et al. 1991; Cowan 1999). Given intra-cohort density dependence preceding that involving adult density,

$R_{x}=\frac{e^{-\alpha(1-D) N_{x}}}{1+\alpha D S_{x}}$.

Just as occurred when density dependence processes were allowed to act simultaneously, Eqs. 9 and 10 simplify to Ricker and Beverton-Holt formulas with consideration of strict inter- and intra-cohort density dependence processes (i.e., $D=0$ and 1), respectively.

\section{References}

Alcala AC et al (2005) A long-term, spatially replicated experimental test of the effect of marine reserves on local fish yields. Can J Fish Aquat Sci 62:98-108. doi:10.1139/f04-176

Anderson CNK et al (2008) Why fishing magnifies fluctuations in fish abundance. Nature 452:835-839. doi:10.1038/nature06851

Armstrong CW, Skonhoft A (2006) Marine reserves: a bio-economic model with asymmetric density dependent migration. Ecol Econ 57:466-476. doi:10.1016/j.ecolecon.2005.05.010

Armsworth PR, Roughgarden JE (2003) The economic value of ecological stability. Proc Natl Acad Sci USA 100:7147-7151. doi:10.1073/pnas.0832226100

Bene C, Tewfik A (2001) Fishing effort allocation and fishermen's decision making process in a multi-species small-scale fishery: analysis of the conch and lobster fishery in Turks and Caicos Islands. Hum Ecol 29:157-186. doi:10.1023/A:1011059830170
Beverton RJH, Holt SJ (1957) On the dynamics of exploited fish populations. H.M.S.O., London

Cardinale M, Svedang H (2004) Modelling recruitment and abundance of Atlantic cod, Gadus morhua, in the eastern SkagerrakKattegat (North Sea): evidence of severe depletion due to a prolonged period of high fishing pressure. Fish Res 69:263-282. doi:10.1016/j.fishres.2004.04.001

CDFG (2008) California Department of Fish and Game

Clark CW (1990) Mathematical Economics: the Optimal Management of Renewable Resources, 2nd edn. Wiley, New York

Costello C, Deacon R (2007) The efficiency gains from fully delineating rights in an ITQ fishery. Mar Resour Econ 22:347-361

Cowan DF (1999) Method for assessing relative abundance, size distribution, and growth of recently settled and early juvenile lobsters (Homarus americanus) in the lower intertidal, zone. J Crustac Biol 19:738-751. doi:10.2307/1549298

Davis GE (2005) Science and society: marine reserve design for the California channel islands. Conserv Biol 19:1745-1751. doi:10.1111/j.1523-1739.2005.00317.x

Day R et al (2004) Effects of density and food supply on postlarval abalone: Behaviour, growth and mortality. J Shellfish Res 23:1009-1018

Dulvy NK et al (2003) Extinction vulnerability in marine populations. Fish Fish 4:25-64. doi:10.1046/j.1467-2979.2003.00105.x

Durant JM et al (2008a) Northeast arctic cod population persistence in the Lofoten-Barents Sea system under fishing. Ecol Appl 18:662-669. doi:10.1890/07-0960.1

Durant JM et al (2008b) Northeast arctic cod population persistence in the Lofoten-Barents sea system under fishing. Ecol Appl 18:662669. doi:10.1890/07-0960.1

Essington TE et al (2006) Fishing through marine food webs. Proc Natl Acad Sci USA 103:3171-3175. doi:10.1073/pnas.0510964103

Folkvord A (1997) Ontogeny of cannibalism in larval and juvenile fish with special emphasis on cod, Gadus morhua L. Chapman and Hall, London

Fujita R, Bonzon K (2005) Rights-based fisheries management: An environmentalist perspective. Rev Fish Biol Fish 15:309-312. doi:10.1007/s11160-005-4867-y

Gårdmark A et al (2006) Density-dependent body growth reduces the potential of marine reserves to enhance yields. J Appl Ecol 43:61-69. doi:10.1111/j.1365-2664.2005.01104.x

Gaylord B et al (2005) Marine reserves exploit population structure and life history in potentially improving fisheries yields. Ecol Appl 15:2180-2191. doi:10.1890/04-1810

Gerber LR et al (2003) Population models for marine reserve design: a retrospective and prospective synthesis. Ecol Appl 13:S47-S64. doi:10.1890/1051-0761(2003)013[0047:PMFMRD]2.0.CO;2

Gordon HS (1954) The economic-theory of a common property resource: The fishery. J Polit Econ 62:124-142. doi:10.1086/ 257497

Grafton RQ (1996) Individual transferable quotas: theory and practice. Rev Fish Biol Fish 6:5-20. doi:10.1007/BF00058517

Grafton RQ et al (2000) Private property and economic efficiency: A study of a common-pool resource. J Law Econ 43:679-713. doi:10.1086/467469

Hamilton SL et al (2008) Postsettlement survival linked to larval life in a marine fish. Proc Natl Acad Sci USA 105:1561-1566. doi:10.1073/pnas.0707676105

Hannesson R (1991) From common fish to rights based fishing fisheries management and the evolution of exclusive rights to fish. Eur Econ Rev 35:397-407. doi:10.1016/0014-2921(91)90141-5

Hannesson R (2007) A note on the "stock effect". Mar Resour Econ 22:69-75

Hart DR, Sissenwine MP (2009) Marine reserve effects on fishery profits: a comment on White et al. Ecology Letters 12:E9-E11. doi:10.1111/j.1461-0248.2008.01272.x 
Hastings A, Botsford LW (1999) Equivalence in yield from marine reserves and traditional fisheries management. Science 284:15371538. doi: $10.1126 /$ science. 284.5419 .1537

Hiddink JG et al (2006) Cumulative impacts of seabed trawl disturbance on benthic biomass, production, and species richness in different habitats. Can J Fish Aquat Sci 63:721-736. doi:10.1139/f05-266

Hilborn R et al (2003) State of the world's fisheries. Annu Rev Environ Resour 28:359-399. doi:10.1146/annurev.energy.28. 050302.105509

Hilborn R et al (2005) Institutions, incentives and the future of fisheries. Philos Trans R Soc B-Biological Sci 360:47-57. doi:10.1098/rstb.2004.1569

Hixon MA, Jones GP (2005) Competition, predation, and densitydependent mortality in demersal marine fishes. Ecology 86:2847-2859. doi:10.1890/04-1455

Hobson ES et al (2001) Interannual variation in predation on first-year Sebastes spp. by three northern California predators. Fish B-Noaa 99:292-302

Johnson DW (2006a) Density dependence in marine fish populations revealed at small and large spatial scales. Ecology 87:319-325. doi:10.1890/04-1665

Johnson DW (2006b) Predation, habitat complexity, and variation in density-dependent mortality of temperate reef fishes. Ecology 87:1179-1188. doi:10.1890/0012-9658(2006)87[1179:PHCAVI] 2.0.CO;2

Johnson DW (2007) Habitat complexity modifies post-settlement mortality and recruitment dynamics of a marine fish. Ecology 88:1716-1725. doi:10.1890/06-0591.1

Joyce IT (1997) The spiny-lobster fishery in Cuba. Geogr Rev 87:484-503. doi:10.2307/215227

Kaczynski VM, Fluharty DL (2002) European policies in West Africa: who benefits from fisheries agreements? Mar Policy 26:75-93. doi:10.1016/S0308-597X(01)00039-2

Kaplan DM (2006) Alongshore advection and marine reserves: consequences for modeling and management. Mar Ecol Prog Ser 309:11-24. doi:10.3354/meps309011

Lauck $\mathrm{T}$ et al (1998) Implementing the precautionary principle in fisheries management through marine reserves. Ecol Appl 8:S72S78

Lipcius RN, Stockhausen WT (2002) Concurrent decline of the spawning stock, recruitment, larval abundance, and size of the blue crab Callinectes sapidus in Chesapeake Bay. Mar Ecol Prog Ser 226:45-61. doi:10.3354/meps226045

Love MS et al (1991) The ecology of substrate-associated juveniles of the genus Sebastes. Environ Biol Fishes 30:225-243. doi:10.1007/BF02296891

Marteinsdottir G, Begg GA (2002) Essential relationships incorporating the influence of age, size and condition on variables required for estimation of reproductive potential in Atlantic cod Gadus morhua. Mar Ecol Prog Ser 235:235-256. doi:10.3354/meps 235235

May RM (2004) Uses and abuses of mathematics in biology. Science 303:790-793. doi:10.1126/science.1094442

McClanahan TR, Kurtis JD (1991) Population regulation of the rockboring sea-urchin Echinometra mathaei (de Blainville). J Exp Mar Biol Ecol 147:121-146. doi:10.1016/0022-0981(91)90041-T

Meester GA et al (2004) Designing marine reserves for fishery management. Manage Sci 50:1031-1043. doi:10.1287/ mnsc. 1040.0222

Minto C et al (2008) Survival variability and population density in fish populations. Nature 452:344-348. doi:10.1038/nature06605

Myers RA, Worm B (2003) Rapid worldwide depletion of predatory fish communities. Nature 423:280-283. doi:10.1038/nature01610

Nash RDM et al (2000) Regional variability in the dynamics of reproduction and growth of Irish Sea plaice, Pleuronectes platessa L. J Sea Res 44:55-64. doi:10.1016/S1385-1101(00)00046-0
Neubert MG (2003) Marine reserves and optimal harvesting. Ecol Lett 6:843-849. doi:10.1046/j.1461-0248.2003.00493.x

Newell RG et al (2005) Fishing quota markets. J Environ Econ Manage 49:437-462. doi:10.1016/j.jeem.2004.06.005

Norris KS (1963) Functions of temperature in ecology of percoid fish Girella nigricans (Ayres). Ecol Monogr 33:23-62. doi:10.2307/ 1948476

O'Neill MF et al (2003) Comparison of relative fishing power between different sectors of the Queensland trawl fishery, Australia. Fish Res 65:309-321. doi:10.1016/j.fishres.2003.09.022

Officer RA et al (2001) Movement and re-aggregation of the blacklip abalone, Haliotis rubra Leach, after fishing. J Shellfish Res 20:771-779

Osenberg CW et al (2002) Rethinking ecological inference: density dependence in reef fishes. Ecol Lett 5:715-721. doi:10.1046/ j.1461-0248.2002.00377.x

Parrish R (1999) Marine reserves for fisheries management: why not. Cal Coop Ocean Fish 40:77-86

Pelletier D et al (2008) Models and indicators for assessing conservation and fisheries-related effects of marine protected areas. Can J Fish Aquat Sci 65:765-779. doi:10.1139/F08-026

Polacheck T (2006) Tuna longline catch rates in the Indian Ocean: Did industrial fishing result in a $90 \%$ rapid decline in the abundance of large predatory species? Mar Policy 30:470-482. doi:10.1016/ j.marpol.2005.06.016

Queiros AM et al (2006) Effects of chronic bottom trawling disturbance on benthic biomass, production and size spectra in different habitats. J Exp Mar Biol Ecol 335:91-103. doi:10.1016/ j.jembe.2006.03.001

Ralston S, O, Farrell MR (2008) Spatial variation in fishing intensity and its effect on yield. Can J Fish Aquat Sci 65:588-599. doi:10.1139/F07-174

Ricker WE (1954) Stock and recruitment. J Fish Res Board Can 11:559-623

Roberts CM (2007) The Unnatural History of the Sea. Island Press, Washington

Sadovy Y, Domeier M (2005) Are aggregation-fisheries sustainable? Reef fish fisheries as a case study. Coral Reefs 24:254-262. doi:10.1007/s00338-005-0474-6

Sala E et al (2004) Fishing down coastal food webs in the Gulf of California. Fisheries 29:19-25. doi:10.1577/1548-8446(2004)29 [19:FDCFWI]2.0.CO;2

Sanchirico JN (2004) Designing a cost-effective marine reserve network: a bioeconomic metapopulation analysis. Mar Resour Econ 19:41-65

Sanchirico JN (2005) Additivity properties in metapopulation models: implications for the assessment of marine reserves. J Environ Econ Manage 49:1-25. doi:10.1016/j.jeem.2004.03.007

Sanchirico JN et al (2006) When are no-take zones an economically optimal fishery management strategy? Ecol Appl 16:1643-1659. doi:10.1890/1051-0761(2006)016[1643:WANZAE]2.0.CO;2

Sandberg P (2006) Variable unit costs in an output-regulated industry: the fishery. Appl Econ 38:1007-1018. doi:10.1080/0003 6840500405912

Schmitt RJ, Holbrook SJ (2007) The scale and cause of spatial heterogeneity in strength of temporal density dependence. Ecology 88:1241-1249. doi:10.1890/06-0970

Shima JS, Osenberg CW (2003) Cryptic density dependence: effects of covariation between density and site quality in reef fish. Ecology 84:46-52. doi:10.1890/0012-9658(2003)084[0046: CDDEOC]2.0.CO;2

Siegel DA et al (2003) Lagrangian descriptions of marine larval dispersion. Mar Ecol Prog Ser 260:83-96. doi:10.3354/meps260083

Slotte A et al (2006) Egg cannibalism in Barents Sea capelin in relation to a narrow spawning distribution. J Fish Biol 69:187202. doi:10.1111/j.1095-8649.2006.01085.x

Smith C, Reay P (1991) Cannibalism in teleost fish. Rev Fish Biol Fish 1:41-64. doi:10.1007/BF00042661 
Smith MD, Wilen JE (2003) Economic impacts of marine reserves: the importance of spatial behavior. J Environ Econ Manage 46:183206. doi:10.1016/S0095-0696(03)00024-X

Steele MA, Forrester GE (2002) Early postsettlement predation on three reef fishes: effects on spatial patterns of recruitment. Ecology 83:1076-1091

Stefansson G, Rosenberg AA (2005) Combining control measures for more effective management of fisheries under uncertainty: quotas, effort limitation and protected areas. Philos Trans R Soc B-Biological Sci 360:133-146. doi:10.1098/rstb.2004.1579

Stobutzki IC et al (2006) Decline of demersal coastal fisheries resources in three developing Asian countries. Fish Res 78:130-142. doi:10.1016/j.fishres.2006.02.004

Sumaila UR (1998) Protected marine reserves as fisheries management tools: a bioeconomic analysis. Fish Res 37:287-296. doi:10.1016/S0165-7836(98)00144-1

Tomas F et al (2005) Experimental evidence that intra-specific competition in seagrass meadows reduces reproductive potential in the sea urchin Paracentrotus lividus (Lamarck). Sci Mar 69:475-484. doi:10.3989/scimar.2005.69n4475
Verhulst PF (1838) Notice sur la loi que la population suit dans son accroissement. Correspondance Math Phys 10:113-117

Wahle RA (2003) Revealing stock-recruitment relationships in lobsters and crabs: is experimental ecology the key? Fish Res 65:3-32. doi:10.1016/j.fishres.2003.09.004

Webster MS (2004) Density dependence via intercohort competition in a coral-reef fish. Ecology 85:986-994. doi:10.1890/02-0576

White C, Kendall BE (2007) A reassessment of equivalence in yield from marine reserves and traditional fisheries management. Oikos 116:2039-2043. doi:10.1111/j.2007.0030-1299.16167.x

White $\mathrm{C}$ et al (2008) Marine reserve effects on fishery profit. Ecol Lett 11:370-379. doi:10.1111/j.1461-0248.2007.01151.x

White JW, Caselle JE (2008) Scale-dependent changes in the importance of larval supply and habitat to abundance of a reef fish. Ecology 89:1323-1333. doi:10.1890/07-0840.1

Wood LJ et al (2008) Assessing progress towards global marine protection targets: shortfalls in information and action. Oryx 42:340-351. doi:10.1017/S003060530800046X

Worm B et al (2006) Impacts of biodiversity loss on ocean ecosystem services. Science 314:787-790. doi:10.1126/science.1132294 